\title{
Aerosol Therapy During Noninvasive Ventilation or High-Flow Nasal Cannula
}

\author{
Dean R Hess PhD RRT FAARC
}

\author{
Introduction \\ Aerosol Therapy During NIV \\ Evidence for NIV \\ Equipment for NIV \\ Systematic Review \\ Bench Studies \\ Summary of Bench Studies \\ Healthy Volunteers \\ Asthma \\ COPD \\ Cystic Fibrosis \\ Pneumonia \\ Summary of Human Studies \\ Aerosol Delivery During HFNC \\ Approaches to Improve Aerosol Delivery During HFNC \\ Summary of Aerosol Delivery During HFNC \\ Conclusions
}

\begin{abstract}
Noninvasive ventilation (NIV) and high-flow nasal cannula (HFNC) are increasingly used for patients with acute respiratory failure. Some patients receiving these therapies might also benefit from inhaled drug delivery. Thus, it is attractive to combine aerosol therapy with NIV or HFNC. The purpose of this paper is to review the available evidence related to the use of inhaled aerosols with NIV or HFNC. Available evidence supports the delivery of aerosols during NIV. Inhaled bronchodilator response might be improved with the use of NIV in acute asthma, but the evidence is not sufficiently mature to recommend this as standard therapy. Evidence does support aerosol delivery without discontinuation of NIV. Clinical studies on aerosol delivery during HFNC are needed, and based on the available in vitro evidence, it is not possible to make a recommendation for or against aerosol delivery during HFNC. Key words: aerosol; high-flow nasal cannula; inhaler; nebulizer; noninvasive ventilation. [Respir Care 2015;60(6):880-893. (C) 2015 Daedalus Enterprises]
\end{abstract}

\section{Introduction}

Noninvasive ventilation (NIV) and high-flow nasal cannula (HFNC) are increasingly used for patients with acute

Dr Hess is affiliated with the Respiratory Care Department, Massachusetts General Hospital, and the Department of Anesthesia, Harvard Medical School, Boston, Massachusetts. respiratory failure. Some patients receiving these therapies might also benefit from inhaled drug delivery. Thus, it is attractive to combine aerosol therapy with NIV or HFNC. This paper reviews the published literature related to aero-

Dr Hess discloses relationships with Philips Respironics, PARI, Bayer, Merck, UpToDate, McGraw-Hill, Jones \& Bartlett Learning, and the American Board of Internal Medicine. 
sol therapy during NIV or HFNC. Recommendations are provided based upon the available evidence.

\section{Aerosol Therapy During NIV}

\section{Evidence for NIV}

As recently as 25 years ago, it would have been unthinkable to apply positive-pressure ventilation by face mask. Today, however, the use of NIV is considered standard of care for some forms of acute respiratory failure such as COPD exacerbation and acute cardiogenic pulmonary edema. ${ }^{1}$ A recent meta-analysis identified 78 randomized controlled trials that evaluated the effect of NIV on mortality. ${ }^{2}$ In COPD exacerbations, NIV nearly halves mortality rate compared with standard treatment (relative risk of $0.56,95 \%$ CI $0.42-0.74)$. Relevant to the topic of this paper, patients with COPD exacerbations also benefit from inhaled bronchodilator therapy. The evidence is less mature for the use of NIV for acute asthma. ${ }^{3}$ Despite this paucity of evidence, there has been an increase in the proportion of hospitalizations involving NIV by $>400 \%$ in the Healthcare Cost and Utilization Project Nationwide Inpatient Sample: from $0.35 \%$ of all acute asthma cases in 2000 to $1.9 \%$ in 2008, which is an annual increase of 49\%. ${ }^{4}$ Patients with acute asthma benefit from inhaled bronchodilator therapy. It thus seems reasonable to combine aerosol therapy with NIV for patients with obstructive lung disease when both of these therapies are clinically indicated.

\section{Equipment for NIV}

The interface distinguishes NIV from invasive mechanical ventilation. Available interfaces include a nasal mask, nasal pillows, oronasal mask, hybrid devices (combination of pillows and mouth seal), mouthpiece, total face mask, and helmet. The interface selected for an individual patient is usually based on comfort and risk of facial skin breakdown. The total face mask and helmet devices expose a patient's eyes to flow from the ventilator. Therefore, it seems prudent that these devices should not be used for aerosol delivery during NIV, although this has not been studied.

Dr Hess presented a version of this paper at the 53rd RESPIRATORY CARE Journal Conference on Aerosol Drug Delivery in Respiratory Care, held June 6-7, 2014, in St Petersburg, Florida.

Correspondence: Dean R Hess PhD RRT FAARC, Respiratory Care Department, Ellison 401, Massachusetts General Hospital, 55 Fruit Street, Boston, MA 02114. E-mail: dhess@mgh.harvard.edu.

DOI: $10.4187 /$ respcare. 04042
Table 1. PubMed Search Strategy Conducted May 16, 2014

\begin{tabular}{llr}
\hline \hline Search No. & \multicolumn{1}{c}{ Topic } & Items Found \\
\hline 1 & Ventilation (tw) & 100,104 \\
2 & Ventilator (tw) & 18,303 \\
3 & 1 OR 2 & 10,9214 \\
4 & Noninvasive (tw) & 64,058 \\
5 & Mask (tw) & 20,388 \\
6 & BiPAP (tw) & 488 \\
7 & 4,5, OR 6 & 84,232 \\
8 & 3 AND 7 & 6,993 \\
9 & Aerosol (tw) & 22,532 \\
10 & Nebulizer (tw) & 2,657 \\
11 & Inhaler (tw) & 4,776 \\
12 & Bronchodilator (tw) & 19,551 \\
13 & $9,10,11$, OR 12 & 44,699 \\
14 & 8 AND 13 & 152 \\
15 & English (la) & 136 \\
16 & 14 AND 15 \\
\hline tw = search within text words & & \\
la specify article language & & \\
\hline
\end{tabular}

Bi-level ventilators are commonly used for NIV. A blower generates inspiratory and expiratory pressures. These devices use a single-limb circuit with a leak port, which serves as a passive exhalation port for the patient. The leak port is incorporated into the circuit near the patient or in the interface. The position of the leak port is important for aerosol delivery during NIV, and it could potentially be a source of aerosol loss to the environment. Intermediate ventilators are commonly used for patient transport or home-care ventilation. These ventilators may have a single-limb circuit with an active exhalation valve near the patient, although some have a passive leak port similar to bi-level devices. Newer-generation critical care ventilators have modes for NIV, and some compensate well for leaks. ${ }^{5}$ In critical care ventilators, dual-limb circuits are used, and these have inspiratory and expiratory valves and separate hoses for inspiratory and expiratory gases. When critical care ventilators are used for NIV, aerosol delivery through the circuit is such as it would be for invasive ventilation.

\section{Systematic Review}

I conducted a systematic review of the literature related to aerosol delivery during NIV (Table 1). This netted 136 potential papers. From these, 125 papers were discarded as not relevant to the subject. I added 10 additional papers from review of reference lists and my prior knowledge of the subject. This resulted in 21 papers for inclusion in this review (Fig. 1). Of these, 7 were bench studies, and 11 were studies in humans. In addition to these original re- 
search studies, there have been 3 narrative reviews written on the subject. ${ }^{6-8}$

\section{Bench Studies}

Bench studies are useful to elucidate the technical aspects of aerosol delivery during NIV. These data can then be used to inform human studies or to probe mechanisms to explain results of prior human studies.

Chatmongkolchart et $\mathrm{al}^{9}$ conducted an in vitro evaluation of aerosol bronchodilator delivery during NIV to assess the effect of ventilator settings and nebulizer position. A bi-level ventilator with a standard circuit (leak port in the circuit near the connection to the mask) was attached to a lung model simulating spontaneous breathing. Inspiratory and expiratory pressures of 10/5, 15/5, 20/5, 15/10,

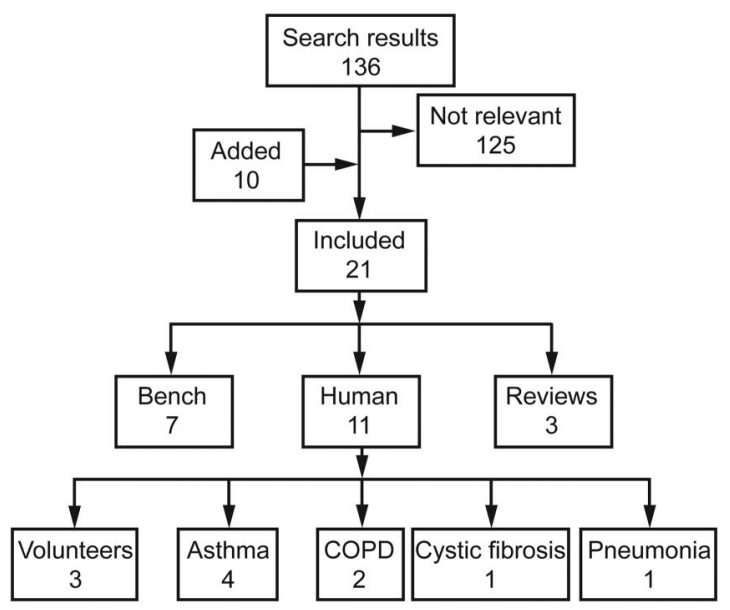

Fig. 1. Flow diagram showing the results of the search strategy related to aerosol therapy with noninvasive ventilation.
20/10, and 25/10 $\mathrm{cm} \mathrm{H}_{2} \mathrm{O}$ were tested at frequencies of 10 and 20 breaths/min. A jet nebulizer was filled with $5 \mathrm{mg}$ of albuterol in $4 \mathrm{~mL}$ of solution, driven with oxygen (8 L/min), and placed at either a proximal position (ventilator outlet) or distal position (between the leak port and lung model connection). Aerosol delivery was estimated by measuring the amount of the albuterol collected on a filter placed at the inlet of the lung model. Albuterol delivery varied from $5.2 \pm 0.4 \%$ to $24.5 \pm 1.3 \%$ of the nominal dose and was affected by the position of the nebulizer, breathing frequency, and ventilator settings. The greatest albuterol delivery was observed with the nebulizer operating at the distal position and a frequency of 20 breaths/min. At this frequency and nebulizer placement, albuterol delivery increased with increasing inspiratory pressure and decreased with increasing expiratory pressure (Fig. 2). Nebulizer flow did not affect ventilator function. The authors concluded that, at the optimum nebulizer position between the leak port and the patient connection and at ventilator settings with high inspiratory and low expiratory pressures, as much as $25 \%$ of the nominal albuterol dose can be made available to the patient during NIV. These results are explained by the position of the nebulizer relative to the leak port, with lower aerosol losses when the nebulizer is placed between the leak port and the patient interface (Fig. 3).

Branconnier and $\mathrm{Hess}^{10}$ evaluated albuterol delivery during NIV to determine the effects of a jet nebulizer or pressurized metered-dose inhaler (pMDI) when the leak port was in the circuit or in the mask. A lung model that simulated spontaneous breathing at 20 breaths/min was used with a bi-level ventilator set for an inspiratory pressure of $15 \mathrm{~cm} \mathrm{H}_{2} \mathrm{O}$ and an expiratory positive airway pres-

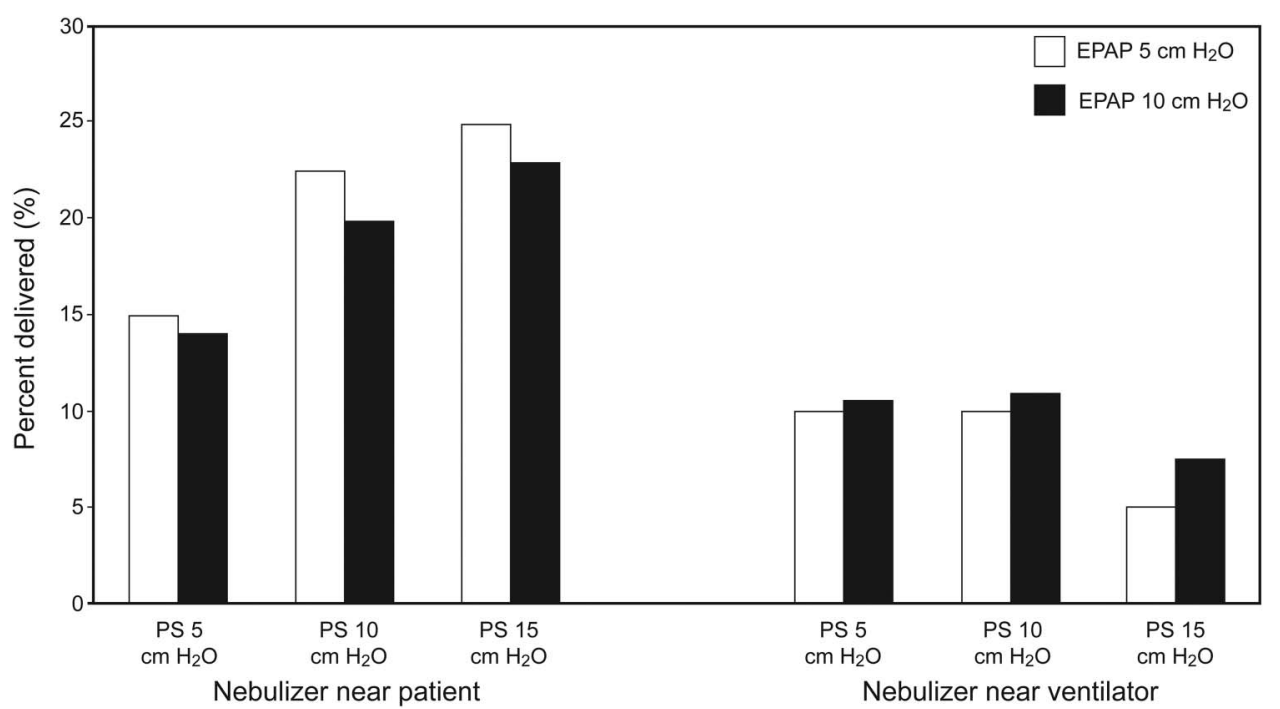

Fig. 2. Effect of ventilator settings and nebulizer position in an in vitro model of aerosol delivery with noninvasive ventilation. EPAP $=$ expiratory positive airway pressure; PS = pressure support. Data from Reference 9. 


\section{Aerosol Therapy During NIV or HFNC}

sure of $5 \mathrm{~cm} \mathrm{H}_{2} \mathrm{O}$. The tidal volume $\left(\mathrm{V}_{\mathrm{T}}\right)$ delivered was $0.4 \mathrm{~L}$. Two mask types were studied: one in which the leak port was incorporated into the circuit and one in which the leak port was incorporated into the mask. The jet nebulizer was filled with $4 \mathrm{~mL}$ of solution containing $5 \mathrm{mg}$ of albuterol, connected by a T-piece directly to the mask, and operated at $8 \mathrm{~L} / \mathrm{min}$ for $15 \mathrm{~min}$. For the pMDI studies, a spacer was placed between the mask and the circuit, and the pMDI was actuated into the spacer, synchronized either with the initiation of inhalation or during the exhalation phase (4 actuations separated by $>15 \mathrm{~s}$ in each case). With the nebulizer, more albuterol was delivered to a filter when the leak port was in the circuit (Fig. 4A). More albuterol was delivered with the nebulizer than with the pMDI. The efficiency of albuterol delivery (percent deliv- ered) was similar for the nebulizer and the pMDI with the leak port in the circuit, but was better with the pMDI with the leak port in the mask (Fig. 4B). Albuterol delivery was significantly less when the MDI was actuated during exhalation.

In a study by Calvert et al, ${ }^{11}$ a bi-level ventilator was attached to a lung model simulating adult breathing. An inspiratory pressure of $20 \mathrm{~cm} \mathrm{H}_{2} \mathrm{O}$ and an expiratory pressure of $5 \mathrm{~cm} \mathrm{H} \mathrm{H}_{2} \mathrm{O}$ were set on the ventilator. Drug delivery was compared when albuterol (5 mg) was nebulized at different positions in the circuit. Optimal albuterol delivery occurred with the leak port between the face mask and the jet nebulizer. The lowest delivery occurred when the nebulizer was placed at the ventilator outlet.
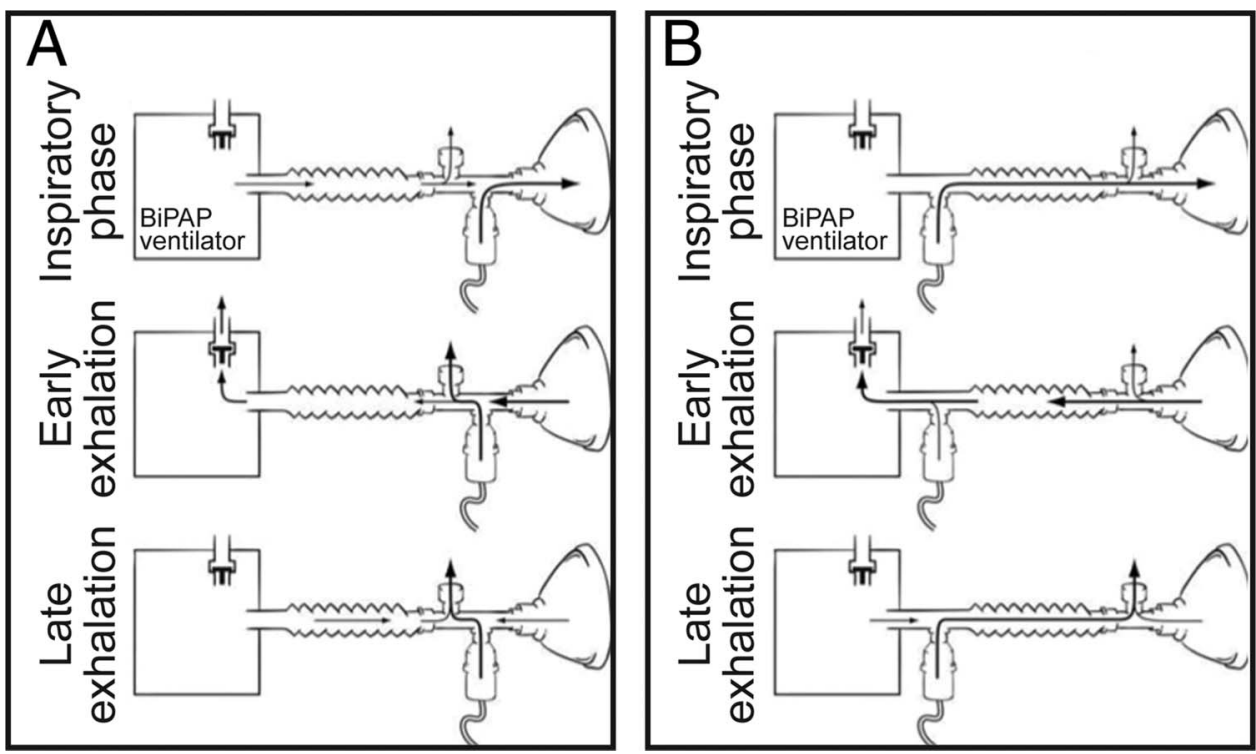

Fig. 3. Schematic showing the effect of leak port on aerosol delivery by a nebulizer. In A, the nebulizer is placed between the leak port and the face mask. Top: During inhalation, the aerosol is directed toward the patient by inspiratory flow. Middle: During early exhalation, the aerosol generated by the nebulizer flows out of the leak port with some retrograde flow of aerosol into the circuit. Bottom: During late exhalation, when expiratory flow declines, some aerosol is cleared from the circuit. In B, the nebulizer is placed closer to the ventilator. Top: During inhalation, the aerosol is delivered to the patient with inspiratory flow, but some of it exits the circuit through the leak port. Middle: During early exhalation, the patient's exhalation dilutes the aerosol in the circuit and directs aerosol from the circuit into the ventilator. Bottom: During late exhalation, when expiratory flow declines, aerosol generated is again directed toward the patient by the nebulizer flow. $\mathrm{BiPAP}=$ bi-level positive airway pressure. From Reference 7, with permission.
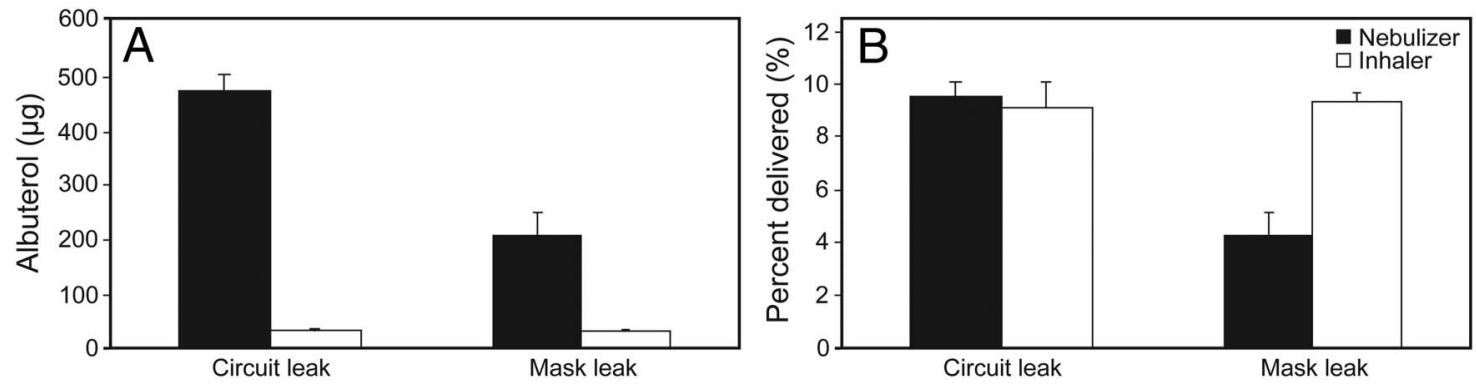

Fig. 4. The Spectrum mask incorporates the leak port into the circuit, whereas the Mirage mask incorporates the leak port into the mask. A: Absolute amount of albuterol delivered with a nebulizer and metered-dose inhaler with the Spectrum and Mirage masks. B: Percent of the nominal dose of albuterol delivered with a nebulizer and metered-dose inhaler with the Spectrum and Mirage masks. From Reference 10. 
Abdelrahim et al ${ }^{12}$ evaluated aerosol delivery using a breathing simulator and a bi-level ventilator with inspiratory and expiratory pressures of 20 and $5 \mathrm{~cm} \mathrm{H}_{2} \mathrm{O}$, an inspiratory-expiratory ratio of $1: 3$, a frequency of 15 breaths/ min, and a $\mathrm{V}_{\mathrm{T}}$ of $500 \mathrm{~mL}$. Terbutaline solution $(5 \mathrm{mg}$ in $2 \mathrm{~mL}$ ) was nebulized using a vibrating-mesh nebulizer (Aeroneb Pro) and a jet nebulizer (Sidestream). The nebulizer was placed either between the leak port and the simulator or between the leak port and the ventilator. More terbutaline was deposited on a filter when the nebulizer was placed between the breathing simulator and the leak port. The amount of drug delivered was greater for the mesh nebulizer than the jet nebulizer due to a smaller dead volume in the mesh device.

An in vitro study was conducted by White et $\mathrm{al}^{13}$ to evaluate the optimal nebulizer position of a mesh nebulizer during pediatric NIV. An upper-airway model was attached to a lung model that simulated spontaneous breathing. A bi-level ventilator with a heated-wire circuit and humidifier was attached to the lung model by a pediatric oronasal mask. Albuterol (5 mg in $3.5 \mathrm{~mL}$ of solution) was delivered with a vibrating-mesh nebulizer at 3 circuit positions: before the humidifier and leak valve, between the humidifier and leak valve, and integrated within the mask and after the leak port. More albuterol was delivered to a filter with the nebulizer integrated into the mask compared with the other testing conditions. Greater drug delivery was observed with the nebulizer placed proximally to the mask than when placed before the humidifier.

Michotte et $\mathrm{al}^{14}$ used an adult lung model of NIV with a bi-level ventilator to compare inhaled and lost doses of 5 nebulizers and the influence of nebulizer position. The lung model was set to generate a frequency of 15 breaths/ min. The bi-level ventilator was set with an inspiratory pressure of $20 \mathrm{~cm} \mathrm{H}_{2} \mathrm{O}$ and an expiratory pressure of $5 \mathrm{~cm} \mathrm{H}_{2} \mathrm{O}$. Three mesh nebulizers (Aeroneb Pro, Aeroneb Solo, and NIVO), one jet nebulizer (Sidestream), and one ultrasonic nebulizer (Servo Ultra) were evaluated. The nebulizers were charged with amikacin $(500 \mathrm{mg}$ in $4 \mathrm{~mL}$ ) and operated either before or after the exhalation port. When positioned between the lung model and the leak port, the mesh nebulizer delivered the highest inhaled dose, the jet nebulizer had the highest expiratory wasted dose, and the ultrasonic nebulizer had the highest total lost dose. When positioned between the ventilator and the leak port, the mesh nebulizers delivered the highest inhaled and expiratory wasted doses. The most efficient nebulizers were the NIVO and Aeroneb Solo when placed between the exhalation port and the lung model.

Dai et $\mathrm{al}^{15}$ used a lung model to investigate the influence of leak port and nebulizer position on aerosol delivery during NIV. They compared 3 leak ports: the singlearch exhalation port, plateau exhalation valve, and whisper swivel. A jet nebulizer was filled with albuterol $(5 \mathrm{mg}$ in
$3 \mathrm{~mL}$ ), driven with oxygen at $8 \mathrm{~L} / \mathrm{min}$, and placed either at a position in the ventilator circuit near the ventilator outlet or between the leak port and the lung model. Inspiratory and expiratory pressures of $15 / 5,15 / 10,25 / 5$, and $25 / 10 \mathrm{~cm} \mathrm{H}_{2} \mathrm{O}$ were used. When the nebulizer was placed between the leak port and the lung model, the single-arch port had the highest aerosol delivery, and the whisper swivel had the lowest aerosol delivery. When the nebulizer was placed near the ventilator outlet, the efficiency of aerosol delivery by the single-arch port was lower compared with the whisper swivel and plateau exhalation valve. Higher inspiratory pressure was associated with increased aerosol delivery. The authors concluded that the type of leak port and the position of the nebulizer in the ventilator circuit have a significant influence on the efficiency of aerosol delivery during NIV.

\section{Summary of Bench Studies}

- The jet nebulizer, pMDI, and mesh nebulizer can deliver a dose to the mask that is likely to be therapeutic.

- The best position for the aerosol generator is between the leak port and the mask.

- The pMDI might be more efficient than a nebulizer when the leak port is in the mask.

- When using a nebulizer, more aerosol is delivered with a higher level of pressure support and less aerosol is delivered with a higher level of expiratory pressure.

- Unlike invasive ventilation, placing the nebulizer near the ventilator reduces aerosol delivery during NIV.

- The effect of humidification on aerosol delivery during NIV has not been studied, so it is unknown whether aerosol delivery is reduced when the gas is humidified.

- Inspiratory-only delivery of aerosol from a nebulizer during NIV has not been studied because no commercially available, nebulizer-triggering system is available for use during NIV.

This information is summarized in Figure 5.

\section{Healthy Volunteers}

Reychler et al ${ }^{16}$ compared lung deposition of amikacin delivered by a jet nebulizer (Sidestream) used alone or coupled to a CPAP device (Boussignac). Amikacin was nebulized with both devices in 6 healthy subjects for $5 \mathrm{~min}$. There was a 1-week washout period between each nebulization session. Monitoring of amikacin concentration in urine indirectly assessed lung deposition. The amount of amikacin excreted in the urine was significantly lower with CPAP than with the nebulizer alone. The residual amount of amikacin in the nebulizer was higher with CPAP 


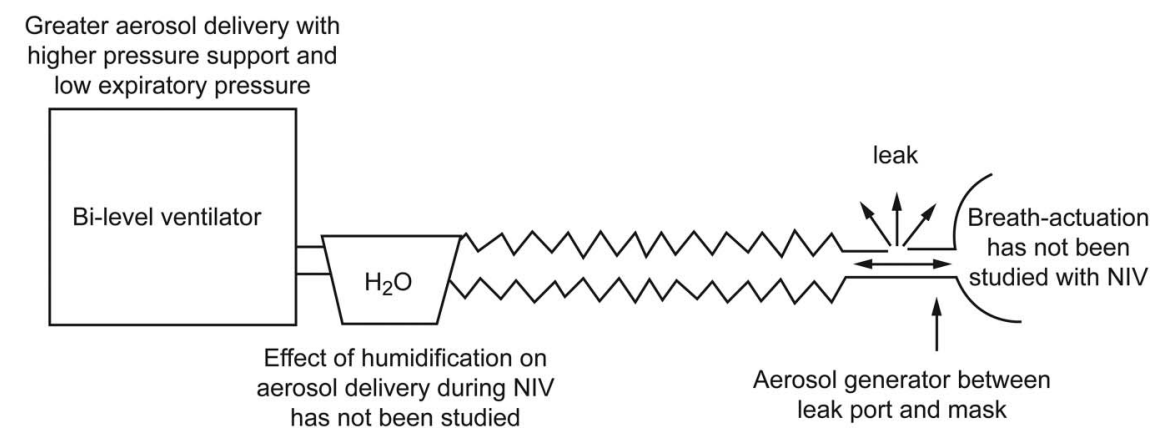

Fig. 5. Factors that have been found to affect aerosol delivery during noninvasive ventilation (NIV) and areas requiring further research.

than with the nebulizer alone. The authors concluded that the amount of amikacin delivered to healthy lungs is 2.5fold lower with CPAP than with the nebulizer alone for the same nebulization time. However, there is a potential effect other than CPAP that might have confounded the results, that is, placement of the Boussignac device might have affected the performance of the breath-enhanced nebulizer, which was not considered by the authors.

França et al ${ }^{17}$ compared pulmonary radioaerosol deposition during jet nebulization with NIV versus spontaneous breathing to measure lung deposition by scintigraphy and to evaluate the correlation among lung deposition, inspiratory flow, and $\mathrm{V}_{\mathrm{T}}$. They enrolled 13 subjects with normal spirometry. A bi-level ventilator was used with an inspiratory pressure of $12 \mathrm{~cm} \mathrm{H}_{2} \mathrm{O}$ and an expiratory pressure of $5 \mathrm{~cm} \mathrm{H}_{2} \mathrm{O}$. An oronasal mask was used, but the site of placement of the nebulizer in the NIV circuit is unclear. A radioaerosol (technetium) was placed in the nebulizer. There was a decrease in aerosol lung deposition with nebulization and NIV compared with spontaneous breathing (mean counts of 200,510 $\pm 11,012$ with spontaneous breathing vs $106,093 \pm 2,811$ with NIV). During spontaneous breathing, there was a significant correlation between $\mathrm{V}_{\mathrm{T}}$ and aerosol deposition in the lungs and also between inspiratory flow and aerosol deposition in the lungs. However, there was no correlation between $\mathrm{V}_{\mathrm{T}}$ and pulmonary deposition during NIV. The authors concluded that, although there was an increase in $\mathrm{V}_{\mathrm{T}}$ associated with a higher inspiratory flow during NIV, this did not result in an increase in pulmonary deposition.

The objective of the study by Maccari18 et al was to determine the effect of spontaneous breathing and NIV on lung technetium-99m deposition in subjects with normal lungs. The study enrolled 13 volunteers for technetium radioaerosol nebulization during spontaneous breathing, CPAP at $10 \mathrm{~cm} \mathrm{H}_{2} \mathrm{O}$, and bi-level ventilation with inspiratory and expiratory pressures of 15 and $5 \mathrm{~cm} \mathrm{H}_{2} \mathrm{O}$. The nebulizer was placed between the mask and the leak port. Aerosol deposition was evaluated by scintigraphy after 10 min of inhalation. The 3 techniques showed comparable lung deposition. There was no difference between aero- sol deposition in the right lung, left lung, or trachea. These data suggest that, in individuals with normal lungs, aerosol delivery is not reduced during CPAP or NIV.

\section{Asthma}

Parkes and Bersten ${ }^{19}$ evaluated aerosol kinetics and bronchodilator efficacy during CPAP delivered by face mask. The effect of CPAP at $10 \mathrm{~cm} \mathrm{H}_{2} \mathrm{O}$ at a flow of $50 \mathrm{~L} / \mathrm{min}$ on the delivery of technetium-labeled aerosol generated by a jet nebulizer was measured using a bench model of spontaneous breathing. In a follow-up clinical study, the bronchodilator responses to incremental doses of inhaled albuterol were measured in 9 stable subjects with asthma in a random sequence of jet nebulizer (control) or jet nebulizer while receiving CPAP with a tight-fitting face mask. CPAP significantly reduced total aerosol delivery to the face mask from $6.85 \%$ to $1.3 \%$ of the nebulizer charge. In the clinical study, a significant bronchodilator response to albuterol occurred with both the jet nebulizer alone and with CPAP. The shape of the dose-response curves and the magnitude of $\mathrm{FEV}_{1}$ increase were identical for CPAP and control conditions. The authors concluded that, despite a reduction in aerosol presented to the mask, the bronchodilator response to inhaled albuterol in stable subjects with asthma was not affected when CPAP was delivered by face mask.

The first study to explore the use of NIV in subjects with acute asthma was published by Pollack et al. ${ }^{20}$ This prospective randomized study was conducted in the emergency department of an urban tertiary care teaching hospital. The study population consisted of subjects between the ages of 18 and $40 \mathrm{y}$ who presented with acute asthma. Subjects were randomly assigned to receive 2 doses of albuterol by aerosol ( $2.5 \mathrm{mg}$ in $3 \mathrm{~mL}$ of saline), $20 \mathrm{~min}$ apart, delivered either by a nebulizer $(n=40)$ or during NIV $(n=60)$. A bi-level ventilator (inspiratory pressure of $10 \mathrm{~cm} \mathrm{H}_{2} \mathrm{O}$, expiratory pressure of $5 \mathrm{~cm} \mathrm{H}_{2} \mathrm{O}$ ) and nasal mask were used. The position of the nebulizer in the circuit was not reported. Subjects who received albuterol during NIV had a significantly greater increase in peak 


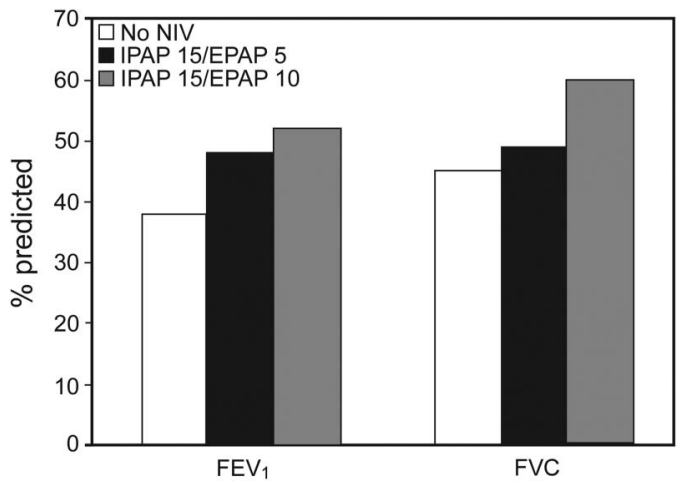

Fig. 6. FEV 1 and FVC for the control group (without noninvasive ventilation [NIV]), NIV with an inspiratory pressure (IPAP) of $15 \mathrm{~cm} \mathrm{H} \mathrm{H}_{2} \mathrm{O}$ and expiratory pressure (EPAP) of $5 \mathrm{~cm} \mathrm{H}_{2} \mathrm{O}$, and NIV with an IPAP of $15 \mathrm{~cm} \mathrm{H}_{2} \mathrm{O}$ and an EPAP of $10 \mathrm{~cm} \mathrm{H}_{2} \mathrm{O}$. Data from Reference 21.

expiratory flow ( $211 \pm 89$ to $357 \pm 108 \mathrm{~L} / \mathrm{min}$ for NIV vs $183 \pm 60$ to $280 \pm 87 \mathrm{~L} / \mathrm{min}$ for nebulizer alone). Oxygen saturation, pulse rate, and breathing frequency changes were similar for the 2 groups. The results of this study showed, for the first time, that albuterol delivery during NIV is not only feasible but might offer some benefit in the setting of acute asthma.

Brandão et $\mathrm{al}^{21}$ conducted a randomized controlled trial in subjects with acute asthma to evaluate the effect of a jet nebulizer alone or with NIV at 2 levels of expiratory pressure. Subjects $(N=36)$ presented to the emergency department with an $\mathrm{FEV}_{1}<60 \%$ of predicted. NIV was administered with a bi-level ventilator and inspiratory and expiratory pressures of 15 and $5 \mathrm{~cm} \mathrm{H}_{2} \mathrm{O}$ or 15 and $10 \mathrm{~cm} \mathrm{H}_{2} \mathrm{O}$. The authors did not indicate the position of the nebulizer in the circuit or whether a nasal or oronasal mask was used. The aerosol bronchodilators were $2.5 \mathrm{mg}$ of fenoterol and $0.25 \mathrm{mg}$ of ipratropium in $4 \mathrm{~mL}$ of saline. There was a greater improvement in spirometric indices $30 \mathrm{~min}$ after bronchodilator administration with the use of NIV (Fig. 6). There appeared to be a dose-dependent response, with the greatest increase in the group receiving inspiratory and expiratory pressures of 15 and $10 \mathrm{~cm} \mathrm{H}_{2} \mathrm{O}$. These results suggest that mechanical bronchodilation provided by NIV might improve inhaled bronchodilator delivery and deposition in the lungs.

Galindo-Filho et $\mathrm{al}^{22}$ conducted a study to assess the effects of coupling $\beta$-agonist nebulization and NIV during asthma exacerbations. Specifically, they evaluated radioaerosol pulmonary deposition using scintigraphy and cardiopulmonary parameters to correlate pulmonary function with radioaerosol deposition index, radioaerosol penetration index, and pulmonary clearance. The authors randomized adults with moderate-to-severe acute asthma to a control group (nebulizer alone, $n=11$ ) or an experimental group (NIV + nebulizer group, $n=10$ ). All subjects
Table 2. Changes in Pulmonary Function Parameters in Subjects Receiving Inhaled Bronchodilators Without and With NIV

\begin{tabular}{lccc}
\hline \hline & $\begin{array}{c}\text { Nebulizer Control } \\
\text { Group }\end{array}$ & $\begin{array}{c}\text { NIV + Nebulizer } \\
\text { Group }\end{array}$ & $P$ \\
\hline FEV $_{1}, \%$ predicted & & & \\
$\quad$ Before & $44.2 \pm 18.7$ & $51.3 \pm 11.5$ & .44 \\
After & $57.4 \pm 15.3$ & $75.3 \pm 15.7$ & $<.001$ \\
Gain, \% & $29.8 \pm 8.9$ & $46.7 \pm 0.5$ & .02 \\
FVC, \% predicted & & & \\
Before & $43.1 \pm 18.7$ & $50.2 \pm 11.3$ & .74 \\
After & $53.1 \pm 12.8$ & $70.9 \pm 15.1$ & .006 \\
Gain, \% & $23.2 \pm 7.1$ & $41.2 \pm 1.5$ & .02 \\
PEF, \% predicted & & & \\
Before & $41.6 \pm 10.3$ & $40.4 \pm 9.7$ & .70 \\
After & $52.8 \pm 9.9$ & $67.6 \pm 19.1$ & .04 \\
Gain, \% & $26.9 \pm 12.1$ & $67.3 \pm 38.3$ & .01 \\
Inspiratory capacity, & & & \\
$\quad \%$ predicted & & & .79 \\
Before & & & \\
After & & & \\
Gain, \% & $72.4 \pm 15.5$ & $59.9 \pm 15.8$ & \\
& $31.2 \pm 9.1$ & $54.9 \pm 28.8$ & .01
\end{tabular}

Data from Reference 22. Values are mean $\pm \mathrm{SD}$. The level of significance was $P<.05$ (determined by the Student $t$ test for independent samples). NIV = noninvasive ventilation $\mathrm{PEF}=$ peak expiratory flow

inhaled bronchodilators for $9 \mathrm{~min}$, after which deposition and pulmonary clearance were assessed at $0,15,30,45$, and $60 \mathrm{~min}$. An oronasal mask was used, and the NIV settings were an inspiratory pressure of $12 \mathrm{~cm} \mathrm{H}_{2} \mathrm{O}$ and an expiratory pressure of $4 \mathrm{~cm} \mathrm{H}_{2} \mathrm{O}$. The NIV + nebulizer group had improvements from baseline values in $\mathrm{FEV}_{1}$, FVC, peak expiratory flow, and inspiratory capacity compared with the control group (Table 2). Interestingly, no differences were observed between groups regarding radioaerosol deposition index or pulmonary clearance.

The observation by Galindo-Filho et $\mathrm{al}^{22}$ of an improvement in lung function without an increase in aerosol deposition during NIV suggests that there might be a bronchodilator effect of NIV unrelated to aerosol bronchodilator delivery. This is supported by the improvement in spirometry shown by Brandão et $\mathrm{a}^{21}$ with a higher level of expiratory pressure. Soroksky et $\mathrm{al}^{23}$ reported a more rapid improvement in $\mathrm{FEV}_{1}$ during NIV. In that study, aerosol bronchodilators were given during interruption of NIV (ie, not in line with NIV). Soma et $\mathrm{al}^{24}$ randomized subjects to inspiratory and expiratory pressures of 6 and $4 \mathrm{~cm} \mathrm{H}_{2} \mathrm{O}$ or 8 and $6 \mathrm{~cm} \mathrm{H}_{2} \mathrm{O}$ or to a control group (no NIV). Inhaled bronchodilators were not administered to either group. There was a dose-response improvement in $\mathrm{FEV}_{1}$, with the greatest improvement in the group that received the highest pressures during NIV. Gupta et $\mathrm{al}^{25}$ reported that, in subjects with severe acute asthma, the addition of NIV to 


\section{Aerosol Therapy During NIV or HFNC}

standard medical therapy accelerated the improvement in lung function, decreased the inhaled bronchodilator requirement, and shortened the ICU and hospital stay. These data suggest that NIV might have a bronchodilator effect independent of the delivery of inhaled bronchodilators. Further study is necessary to determine the relative effects of airway pressure and inhaled bronchodilator delivery and the potential additive effects.

\section{COPD}

One option for administration of inhaled medications to patients receiving NIV is to remove the mask and provide aerosol therapy in the usual way. The concern is that patients might decompensate when NIV is discontinued. Mukhopadhyay et $\mathrm{al}^{26}$ studied the effects of withdrawing NIV during COPD exacerbation for the delivery of inhaled medications. They measured accessory muscle use, dyspnea, heart rate, breathing frequency, blood pressure, and arterial blood gases during NIV, 10 min after cessation of NIV, after treatment with albuterol (5 mg) and ipratropium $(500 \mu \mathrm{g})$, and again after restitution of NIV. The study enrolled 19 subjects. There were no significant changes in physiologic parameters and oxygenation between NIV and aerosol therapy periods. The authors concluded that shortterm cessation of NIV for nebulizer treatment did not result in distress, discomfort, or physiologic instabilities. On closer examination, one sees that the subjects received NIV for only 10 min before the mask was removed for NIV. This might not have been sufficient time to acclimate to the effects of NIV. In addition, the dyspnea scores were low, so it is unclear whether NIV was indicated. There was also no change in $\mathrm{P}_{\mathrm{aCO}}$ when NIV was discontinued, suggesting that the subjects might not have benefited from NIV.

Nava et $\mathrm{al}^{27}$ investigated the clinical response to equivalent doses of albuterol delivered by a pMDI during NIV, during spontaneous breathing using a spacer, and during intermittent positive-pressure breathing. This was a prospective, randomized, placebo-controlled study of 18 stable subjects with COPD. NIV was administered with a critical care ventilator using volume-assured pressure support with dry gas and an oronasal mask. Albuterol inhalation resulted in a significant improvement in $\mathrm{FEV}_{1}$ compared with a placebo with each mode of administration. The FVC significantly increased compared with a placebo only with pMDI delivery during NIV. In a second set of experiments of 8 subjects to ascertain the possible effect of NIV on pulmonary function tests, the FVC significantly improved from baseline values after the delivery of placebo or albuterol by pMDI during NIV, but the FEV 1 increased significantly only after albuterol delivery. The authors concluded that delivery of bronchodilators by pMDI during NIV is feasible and induces a significant bronchodilator effect compared with a placebo.

\section{Cystic Fibrosis}

Aerosols are commonly used to deliver drugs to the lungs of patients with cystic fibrosis. The aim of the study by Fauroux et $\mathrm{al}^{28}$ was to assess the effectiveness of NIV in increasing aerosol deposition in the lungs of children with cystic fibrosis. An in vitro study demonstrated that coupling a breath-actuated nebulizer with a ventilator did not impair the function of either device. The system consisted of a ventilator capable of pressure support, a mouthpiece, and a breath-actuated nebulizer placed between the circuit and mouthpiece. An in vivo study enrolled 18 children with clinically stable cystic fibrosis, each of whom underwent both standard nebulizer therapy and a pressure support session. A 4-mL solution of technetium was placed into the nebulizer. Subjects inhaled the aerosol through a mouthpiece while seated and wearing a nose clip. Aerosol deposition in the lungs was assessed in a posterior view for 10 min while subjects were breathing the aerosol. The time-activity nebulization curve was linear in all subjects, with higher slopes during pressure support than during the control session. Deposition efficacy (as a percentage of nebulizer output) was significantly better during the pressure support session than during the control session. No differences in the regional deposition pattern or in homogeneity of uptake were observed. The authors concluded that using NIV with pressure support enhanced total lung aerosol deposition without increasing particle impaction in the proximal airways.

\section{Pneumonia}

Iosson $^{29}$ reported the case of a 42-y-old intravenous drug user who received NIV as part of her treatment for fungal pneumonia and septicemia. NIV was administered with a bi-level ventilator. She received nebulized albuterol and ipratropium by NIV with an oronasal mask. During an inhaled aerosol treatment, her right pupil became fixed and dilated. Examination of the cranial nerves showed no other abnormalities. A computed tomography scan of her head, performed to search for an intracranial cause of the partial palsy of the right third cranial nerve, was normal. The NIV mask was found to fit poorly and allowed a leak to the right eye. The anisocoria resolved within $24 \mathrm{~h}$ after ipratropium was discontinued. Although the indication for NIV and inhaled aerosol in this case is unclear, it does make the important point to be careful not to allow aerosol to leak into the eyes when administered during NIV. 


\section{Aerosol Therapy During NIV or HFNC}

\section{Summary of Human Studies}

- Available evidence supports that aerosols can be delivered effectively during NIV, so it is not necessary to discontinue NIV for aerosol administration.

- For acute asthma, there may be an additive effect of the mechanical bronchodilation properties of NIV and the effects of inhaled bronchodilators.

- For acute asthma, there seems to be a dose relationship between the pressure applied during NIV and the inhaled bronchodilator response.

- When aerosols are administered during NIV, care should be taken to avoid leak of aerosol into the eyes of the patient.

- Evidence is not sufficiently robust to recommend routine use of NIV for aerosol delivery.

\section{Aerosol Delivery During HFNC}

There has been an explosion of interest in the use of HFNC. In Respiratory CARE alone, there have been 20 papers published from 2004 to 2014. Given the interest in HFNC, it is not surprising that there might also be interest in combining this therapy with aerosol delivery. I was able to identify 3 bench studies evaluating aerosol delivery by a nasal cannula. I was not able to identify any studies in human subjects.

The goal of the study by Bhashyam et $\mathrm{al}^{30}$ was to evaluate the potential for delivering aerosols by a nasal cannula by in vitro studies of aerosol output and particle size. They evaluated a mesh nebulizer placed downstream of a heated-humidification system and a nasal cannula. Adult, pediatric, and infant cannulas were tested with and without a breathing simulator. The cannulas were driven by an oxygen flow of $3 \mathrm{~L} / \mathrm{min}$. Dose quantification was performed using radioisotope techniques. Aerosol particle size measurements were made from the nebulizer, the heating tube, and the prongs of adult and pediatric cannulas using laser-diffraction techniques. The total cannula output ranged from 8.4 to $25.1 \%$ and from 18.6 to $26.9 \%$ of the nominal dose placed into the nebulizer both with and without the breathing simulator, respectively. Volume median diameters were $2.2 \pm 0.2 \mu \mathrm{m}$ from the adult cannula and $1.9 \pm 0.3 \mu \mathrm{m}$ from the pediatric cannula. Ninety percent of the aerosol volume was smaller than $4.2 \pm 0.4 \mu \mathrm{m}$ (adult) and $3.8 \pm 0.5 \mu \mathrm{m}$ (pediatric). System losses were highest in the nebulizer-humidifier connectors, heated tube, and humidifier. Losses in the nebulizer were very low (2.2-3.5\%). The authors concluded that aerosols could be efficiently delivered through an HFNC system. However, it is important to note that flows commonly used for HFNC in adults are $30-50 \mathrm{~L} / \mathrm{min}$, much greater than the $3 \mathrm{~L} / \mathrm{min}$ used in this study.

Ari et $\mathrm{al}^{31}$ conducted an in vitro comparison of a helium-oxygen mixture (heliox) and oxygen in aerosol delivery using pediatric HFNC. A mesh nebulizer was placed on the inspiratory inlet of a heated humidifier, and a heated-wire circuit was attached to a pediatric nasal cannula. Breathing parameters were a $\mathrm{V}_{\mathrm{T}}$ of $100 \mathrm{~mL}$, a frequency of 20 breaths/min, and inspiratory time of $1 \mathrm{~s}$. Albuterol $(2.5 \mathrm{mg}$ in $3 \mathrm{~mL}$ ) was administered by pediatric HFNC with oxygen or heliox (80:20 heliox). Flows of 3 and $6 \mathrm{~L} / \mathrm{min}$ were used. The drug was collected on a filter. The inhaled dose was similar with heliox and oxygen at $3 \mathrm{~L} / \mathrm{min}(11.41 \pm 1.54 \%$ and $10.65 \pm 0.51 \%$, respectively). At a flow of $6 \mathrm{~L} / \mathrm{min}$, however, drug deposition was $>2$-fold greater with heliox $(5.42 \pm 0.54 \%)$ than with oxygen $(1.95 \pm 0.50 \%)$. Even with the use of heliox, however, there was an important decrease in the delivered dose with an increase in flow from 3 to $6 \mathrm{~L} / \mathrm{min}$.

Perry et $\mathrm{a}^{32}$ investigated the in vitro inspired dose and particle size distribution of albuterol delivered by a mesh nebulizer by HFNC. Albuterol ( $2.5 \mathrm{mg}$ in $3 \mathrm{~mL}$ ) was delivered by a mesh nebulizer that was connected between a nasal cannula and heated humidifier. Albuterol was collected on a filter mounted onto a breath simulator programmed with age-appropriate breathing patterns: $50 \mathrm{~mL}$, 30 breaths/min, and inspiratory-expiratory ratio of 1:2 for the infant setting; $155 \mathrm{~mL}, 25$ breaths/min, and inspiratory-expiratory ratio of 1:2 for the pediatric setting; and $500 \mathrm{~mL}, 15$ breaths/min, and inspiratory-expiratory ratio of 1:1 for the adult setting. Particle sizing was by cascade impaction. Measurements were made using varying flows of 3,5 , and $8 \mathrm{~L} / \mathrm{min}$ for the infant cannula; $3,5,10$, and $20 \mathrm{~L} / \mathrm{min}$ for the pediatric cannula; and 5, 10, 20, and $40 \mathrm{~L} / \mathrm{min}$ for the adult cannula. The inspired doses (percent of the nominal dose) for each cannula size and flow were $2.5,0.8,0.4$, and $0.2 \%$ for the adult cannula at 5,10 , 20 , and $40 \mathrm{~L} / \mathrm{min}$, respectively; $1.2,0.6,0.1$, and $0 \%$ for the pediatric cannula at $3,5,10$, and $20 \mathrm{~L} / \mathrm{min}$, respectively; and $0.6,0.6$, and $0.5 \%$ for the infant cannula at 3 , 5 , and $8 \mathrm{~L} / \mathrm{min}$, respectively. Most $(60-80 \%)$ of the albuterol dose accumulated within the adapter. For each cannula size, there was a significant decrease in the inspired dose with increasing flows. The dose increased with increasing cannula size at flows of 5,10 , and $20 \mathrm{~L} / \mathrm{min}$. The mass median aerodynamic diameter for all trials was $<5 \mu \mathrm{m}$. The authors concluded that the amount of albuterol delivered by HFNC was lower than the amount expected for a clinical response for the majority of flows and cannula size combinations.

These data, particularly those of Perry et al, ${ }^{32}$ do not encourage the use of aerosol delivery by HFNC. A reasonable estimate of aerosol delivery by mouthpiece is $15 \%$ of the nominal dose, or $0.375 \mathrm{mg}$ of a $2.5-\mathrm{mg}$ nominal 


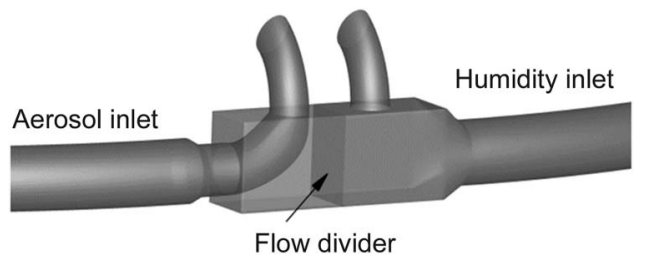

Fig. 7. Enhanced condensational growth nasal cannula. From Reference 45 .

dose, which is much greater than that reported by Perry et al. ${ }^{32}$ However, the benefit of albuterol delivery by HFNC might be for continuous aerosol bronchodilator administration in the setting of acute asthma. Consider that HFNC is used with continuous aerosol bronchodilator set to deliver $15 \mathrm{mg}$ of albuterol/h for an adult by HFNC set at $5 \mathrm{~L} / \mathrm{min}$. Using the results of Perry et al, ${ }^{32}$ this would deliver $0.375 \mathrm{mg}$ of drug/h, exactly the same amount estimated for a single treatment by mouthpiece. This might be more acceptable to the patient and more convenient for the therapist than hourly mouthpiece treatments. This is hypothesis-generating, and future clinical studies should focus on clinical response to aerosol delivery by HFNC, as well as patient and clinician satisfaction and therapy cost.

\section{Approaches to Improve Aerosol Delivery During HFNC}

With HFNC, much aerosol is lost due to impaction in the circuit and in the ambient environment due to the high flows used. Longest and colleagues ${ }^{33-46}$ have been exploring approaches to generate submicron particles, which are less likely to impact in the circuit, but grow large enough in the respiratory tract that they are likely to be deposited in the lungs. This work is preclinical, but has potential for benefit if adapted to clinical use.

One approach uses separate streams of submicron aerosol and heated humidified air to the left and right nostrils, respectively (Fig. 7). ${ }^{45}$ The submicron aerosol is generated by evaporating the output of the small-particle aerosol generator, which has low deposition in the delivery device. There is a subsequent increase to particle size when mixed with the heated humidified gas beyond the nose. This coadministration of heated humidified gas, as used with the HFNC, causes the enhanced condensational growth of the submicron aerosol to the respiratory size range.

A second approach delivers an inhaled submicron aerosol in combination with a hygroscopic excipient. ${ }^{45}$ The submicron aerosol has minimal depositional losses in extrathoracic airways. However, in this case, due to the use of combination drug and hygroscopic excipient particles, when the aerosol is exposed to the natural humidity of the respiratory system, excipient-enhanced growth occurs, pro- ducing droplets of a size suitable for deposition in the lungs.

Longest et $\mathrm{al}^{43}$ used in vitro experiments and computational fluid dynamics simulations to evaluate the delivery of pharmaceutical aerosols by a nasal cannula and the feasibility of enhanced condensational growth with a nasal cannula. They found that submicron aerosols could be formed using a conventional mesh nebulizer and delivered by a nasal cannula with delivery efficiencies of $80-90 \%$. Streamlining the nasal cannula significantly improved the delivery efficiency of both submicron and micron aerosols, but use of submicron particles with enhanced condensational growth delivery resulted in overall lower depositional losses. Golshahi et al ${ }^{45}$ evaluated in vitro aerosol drug delivery by a mesh nebulizer using condensational growth techniques during HFNC with realistic breathing profiles and incorporating intermittent aerosol delivery techniques. They found that intermittent aerosol delivery using realistic breathing profiles of submicron condensational growth aerosols was efficient in delivering nasally administered drugs in an in vitro airway model. These approaches establish the potential for much higher dose delivery of aerosols during HFNC if a clinically applicable system can be developed.

\section{Summary of Aerosol Delivery During HFNC}

- The available in vitro evidence is not sufficiently robust to make a recommendation for or against aerosol delivery during HFNC.

- At high flows, the amount of aerosol delivery is likely to be very low.

- Enhanced condensational growth and excipient-enhanced growth have the potential to improve the feasibility of aerosol delivery during HFNC.

- Clinical studies are necessary to inform the use of HFNC for aerosol delivery as part of patient care.

\section{Conclusions}

Available evidence supports the delivery of aerosols during NIV. Inhaled bronchodilator response might be improved with the use of NIV in acute asthma, but the evidence is not sufficiently mature to recommend this as standard therapy. Evidence supports that aerosols can be delivered without discontinuation of NIV. Clinical studies on aerosol delivery during HFNC are needed, and based on the available in vitro evidence, it is not currently possible to make a recommendation for or against aerosol delivery during HFNC.

\section{REFERENCES}

1. Hess DR. Noninvasive ventilation for acute respiratory failure. Respir Care 2013;58(6):950-972. 


\section{Aerosol Therapy During NIV or HFNC}

2. Cabrini L, Landoni G, Oriani A, Plumari VP, Nobile L, Greco M, et al. Noninvasive ventilation and survival in acute care settings: a comprehensive systematic review and meta-analysis of randomized controlled trials. Crit Care Med 2015;43(4):880-888.

3. Soroksky A, Klinowski E, Ilgyev E, Mizrachi A, Miller A, Ben Yehuda TM, et al. Noninvasive positive pressure ventilation in acute asthmatic attack. Eur Respir Rev 2010;19(115):39-45.

4. Nanchal R, Kumar G, Majumdar T, Taneja A, Patel J, Dagar G, et al. Utilization of mechanical ventilation for asthma exacerbations: analysis of a national database. Respir Care 2014;59(5):644-653.

5. Carteaux G, Lyazidi A, Cordoba-Izquierdo A, Vignaux L, Jolliet P, Thille AW, et al. Patient-ventilator asynchrony during noninvasive ventilation: a bench and clinical study. Chest 2012;142(2):367-376.

6. Ceriana P, Navalesi P, Rampulla C, Prinianakis G, Nava S. Use of bronchodilators during non-invasive mechanical ventilation. Monaldi Arch Chest Dis 2003;59(2):123-127.

7. Dhand R. Aerosol therapy in patients receiving noninvasive positive pressure ventilation. J Aerosol Med Pulm Drug Deliv 2012;25(2): 63-78.

8. Hess DR. The mask for noninvasive ventilation: principles of design and effects on aerosol delivery. J Aerosol Med 2007;20(Suppl 1): S85-S98; discussion S98-S89.

9. Chatmongkolchart S, Schettino GP, Dillman C, Kacmarek RM, Hess DR. In vitro evaluation of aerosol bronchodilator delivery during noninvasive positive pressure ventilation: effect of ventilator settings and nebulizer position. Crit Care Med 2002;30(11):2515-2519.

10. Branconnier MP, Hess DR. Albuterol delivery during noninvasive ventilation. Respir Care 2005;50(12):1649-1653.

11. Calvert LD, Jackson JM, White JA, Barry PW, Kinnear WJ, O'Callaghan C. Enhanced delivery of nebulised salbutamol during non-invasive ventilation. J Pharm Pharmacol 2006;58(11):15531557.

12. Abdelrahim ME, Plant $P$, Chrystyn $H$. In-vitro characterisation of the nebulised dose during non-invasive ventilation. J Pharm Pharmacol 2010;62(8):966-972.

13. White CC, Crotwell DN, Shen S, Salyer J, Yung D, Zheng J, DiBlasi RM. Bronchodilator delivery during simulated pediatric noninvasive ventilation. Respir Care 2013;58(9):1459-1466.

14. Michotte JB, Jossen E, Roeseler J, Liistro G, Reychler G. In vitro comparison of five nebulizers during noninvasive ventilation: analysis of inhaled and lost doses. J Aerosol Med Pulm Drug Deliv 2014;27(6):430-440.

15. Dai B, Kang J, Sun LF, Tan W, Zhao HW. Influence of exhalation valve and nebulizer position on albuterol delivery during noninvasive positive pressure ventilation. J Aerosol Med Pulm Drug Deliv 2014;27(2):125-132.

16. Reychler G, Leal T, Roeseler J, Thys F, Delvau N, Liistro G. Effect of continuous positive airway pressure combined to nebulization on lung deposition measured by urinary excretion of amikacin. Respir Med 2007;101(10):2051-2055.

17. França EE, Dornelas de Andrade AF, Cabral G, Almeida Filho P, Silva KC, Galindo Filho VC, et al. Nebulization associated with bi-level noninvasive ventilation: analysis of pulmonary radioaerosol deposition. Respir Med 2006;100(4):721-728.

18. Maccari JG, Teixeira C, Savi A, de Oliveira RP, Machado AS, Tonietto TF, et al. Nebulization during spontaneous breathing, CPAP, and bi-level positive-pressure ventilation: a randomized analysis of pulmonary radioaerosol deposition. Respir Care 2014;59(4):479484

19. Parkes SN, Bersten AD. Aerosol kinetics and bronchodilator efficacy during continuous positive airway pressure delivered by face mask. Thorax 1997;52(2):171-175.

20. Pollack CV Jr, Fleisch KB, Dowsey K. Treatment of acute bronchospasm with beta-adrenergic agonist aerosols delivered by a nasal bilevel positive airway pressure circuit. Ann Emerg Med 1995;26(5): 552-557.

21. Brandão DC, Lima VM, Filho VG, Silva TS, Campos TF, Dean E, de Andrade AD. Reversal of bronchial obstruction with bi-level positive airway pressure and nebulization in patients with acute asthma. J Asthma 2009;46(4):356-361.

22. Galindo-Filho VC, Brandão DC, Ferreira Rde C, Menezes MJ, Almeida-Filho P, Parreira VF, et al. Noninvasive ventilation coupled with nebulization during asthma crises: a randomized controlled trial. Respir Care 2013;58(2):241-249.

23. Soroksky A, Stav D, Shpirer I. A pilot prospective, randomized, placebo-controlled trial of bilevel positive airway pressure in acute asthmatic attack. Chest 2003;123(4):1018-1025.

24. Soma T, Hino M, Kida K, Kudoh S. A prospective and randomized study for improvement of acute asthma by non-invasive positive pressure ventilation (NPPV). Intern Med 2008;47(6):493-501.

25. Gupta D, Nath A, Agarwal R, Behera D. A prospective randomized controlled trial on the efficacy of noninvasive ventilation in severe acute asthma. Respir Care 2010;55(5):536-543.

26. Mukhopadhyay A, Dela Pena E, Wadden B, Procyshyn M, Keang Lim T. Effects of inhalational bronchodilator treatment during noninvasive ventilation in severe chronic obstructive pulmonary disease exacerbations. J Crit Care 2009;24(3):474.e1-474.e5.

27. Nava S, Karakurt S, Rampulla C, Braschi A, Fanfulla F. Salbutamol delivery during non-invasive mechanical ventilation in patients with chronic obstructive pulmonary disease: a randomized, controlled study. Intensive Care Med 2001;27(10):1627-1635.

28. Fauroux B, Itti E, Pigeot J, Isabey D, Meignan M, Ferry G, et al Optimization of aerosol deposition by pressure support in children with cystic fibrosis: an experimental and clinical study. Am J Respir Crit Care Med 2000;162(6):2265-2271.

29. Iosson N. Images in clinical medicine. Nebulizer-associated anisocoria. N Engl J Med 2006;354(9):e8.

30. Bhashyam AR, Wolf MT, Marcinkowski AL, Saville A, Thomas K, Carcillo JA, Corcoran TE. Aerosol delivery through nasal cannulas: an in vitro study. J Aerosol Med Pulm Drug Deliv 2008;21(2):181188.

31. Ari A, Harwood R, Sheard M, Dailey P, Fink JB. In vitro comparison of heliox and oxygen in aerosol delivery using pediatric high flow nasal cannula. Pediatr Pulmonol 2011;46(8):795-801.

32. Perry SA, Kesser KC, Geller DE, Selhorst DM, Rendle JK, Hertzog $\mathrm{JH}$. Influences of cannula size and flow rate on aerosol drug delivery through the Vapotherm humidified high-flow nasal cannula system. Pediatr Crit Care Med 2013;14(5):e250-e256.

33. Hindle M, Longest PW. Evaluation of enhanced condensational growth (ECG) for controlled respiratory drug delivery in a mouththroat and upper tracheobronchial model. Pharm Res 2010;27(9): 1800-1811.

34. Longest PW, Hindle M. CFD simulations of enhanced condensational growth (ECG) applied to respiratory drug delivery with comparisons to in vitro data. J Aerosol Sci 2010;41(8):805-820.

35. Longest PW, McLeskey JT Jr, Hindle M. Characterization of nanoaerosol size change during enhanced condensational growth. Aerosol Sci Technol 2010;44(6):473-483.

36. Longest PW, Tian G, Hindle M. Improving the lung delivery of nasally administered aerosols during noninvasive ventilation-an application of enhanced condensational growth (ECG). J Aerosol Med Pulm Drug Deliv 2011;24(2):103-118.

37. Tian G, Longest PW, Su G, Hindle M. Characterization of respiratory drug delivery with enhanced condensational growth using an individual path model of the entire tracheobronchial airways. Ann Biomed Eng 2011;39(3):1136-1153.

38. Hindle M, Longest PW. Condensational growth of combination 
drug-excipient submicrometer particles for targeted high-efficiency pulmonary delivery: evaluation of formulation and delivery device. J Pharm Pharmacol 2012;64(9):1254-1263.

39. Longest PW, Hindle M. Condensational growth of combination drugexcipient submicrometer particles for targeted high efficiency pulmonary delivery: comparison of CFD predictions with experimental results. Pharm Res 2012;29(3):707-721.

40. Longest PW, Spence BM, Holbrook LT, Mossi KM, Son YJ, Hindle M. Production of inhalable submicrometer aerosols from conventional mesh nebulizers for improved respiratory drug delivery. J Aerosol Sci 2012;51:66-80.

41. Longest PW, Tian G, Li X, Son YJ, Hindle M. Performance of combination drug and hygroscopic excipient submicrometer particles from a softmist inhaler in a characteristic model of the airways. Ann Biomed Eng 2012;40(12):2596-2610.

42. Golshahi L, Tian G, Azimi M, Son YJ, Walenga R, Longest PW,
Hindle M. The use of condensational growth methods for efficient drug delivery to the lungs during noninvasive ventilation high flow therapy. Pharm Res 2013;30(11):2917-2930.

43. Longest PW, Walenga RL, Son YJ, Hindle M. High-efficiency generation and delivery of aerosols through nasal cannula during noninvasive ventilation. J Aerosol Med Pulm Drug Deliv 2013;26(5): 266-279.

44. Tian G, Longest PW, Li X, Hindle M. Targeting aerosol deposition to and within the lung airways using excipient enhanced growth. J Aerosol Med Pulm Drug Deliv 2013;26(5):248-265.

45. Golshahi L, Longest PW, Azimi M, Syed A, Hindle M. Intermittent aerosol delivery to the lungs during high-flow nasal cannula therapy. Respir Care 2014;59(10):1476-1486.

46. Longest PW, Tian G. Development of a new technique for the efficient delivery of aerosolized medications to infants on mechanical ventilation. Pharm Res 2015;32(1):321-336.

\section{Discussion}

Hill: Great talk as usual, Dean, but I have a question about the use of these aerosols during NIV with asthma. One interpretation might be that there's an independent bronchodilator effect of positive pressure. I think there's a fair amount of evidence to support that idea in the animal literature. I know you're familiar with Soma's study ${ }^{1}$ from Japan. They withheld bronchodilators for an hour and found an improvement of $20 \%$ in $\mathrm{FEV}_{1}$ over oxygen supplementation alone in a group given so-called high-pressure BPAP (bi-level positive airway pressure), which was $8 / 6$ BPAP settings. Not very high, but they did see this improvement. So, with some of the other data, Charlie Pollack's study ${ }^{2}$ and Brandão's study, ${ }^{3}$ where the air flow was better at each level of aerosolization but also of pressure-what do you think of bronchodilation due to positive airway pressure as a way of explaining those findings?

Hess: Absolutely. I think there is a degree of mechanical bronchodilation due to the positive pressure, and Brandão's ${ }^{3}$ data would support that because the bronchodilation was greater with an EPAP (expiratory positive airway) of $10 \mathrm{~cm} \mathrm{H}_{2} \mathrm{O}$ than an EPAP of $5 \mathrm{~cm} \mathrm{H}_{2} \mathrm{O}$. Do you agree?

Hill: Sounds like we're both on the same page on that one.
Restrepo: Dean, very nice presentation. You showed in your systematic review one study ${ }^{4}$ on the use of NIV with bronchodilators in pneumonia. Can you comment a little more on that one? I don't recall having seen it in your presentation, and I'm very intrigued about what exactly they did in that specific condition.

Hess: This was from a case report ${ }^{4}$ of a patient treated for pneumonia and septicemia. The patient was also receiving NIV and in-line aerosol therapy with albuterol and ipratropium bromide. What was interesting in this brief report was anisocoria due to mask leak allowing the aerosol to blow into the eye. Whether NIV or aerosol therapy was indicated is unclear.

Rubin: Have people quantified the amount of aerosol that leaves the leak port? Particularly related to Dr Restrepo's last comment, we're seeing more use of inhaled antimicrobials in patients who are being ventilated, and there's been discussion about using them in mechanical ventilation and NIV for patients with potential ventilator-associated infection. Leakage is certainly a risk for adverse effects for people who may be sensitized, but more so the induction of resistance in environmental bacteria.

Hess: That is a real concern when we deliver inhaled antibiotics with or without NIV. This is based upon lowlevel evidence, a study we did but published only in abstract form a few years ago. ${ }^{5}$ This led to our practice being that the door is closed, we put a sign on the door that the patient is receiving inhaled antibiotics, and caregivers who enter the room wear an N95 mask. Our concern is the one you just raised, that with repeated caregiver exposure to aminoglycosides, resistance develops over time. I don't think we know, but I don't think we want to wait 30 years to find out. Yes, there can be significant aerosol losses through the leak port, but there are significant aerosol losses even if the patient is not on NIV. This also came up a few years ago with concerns about using NIV during SARS (severe acute respiratory syndrome) and H1N1 (avian flu) as far as the contamination of the room and caregivers when patients were on NIV and the flow coming out of the leak port, potentially directed into the face of the caregiver.

Berlinski: I share the same concern that Dr Rubin just expressed, and in fact, in our hospital, for CF (cystic fibrosis) patients who are old enough to use a mouthpiece, we add a Y-piece and a filter to reduce the exposure to the respiratory therapist.

Hess: With that approach, there is still a problem when the patient takes 
the nebulizer out of his or her mouth and we're still blowing the aerosol into the room.

Berlinski: I think that the evidence for exposure of RTs (respiratory therapists) to inhaled aerosols and an increase in respiratory conditions is there.

Hess: You're referring to the study by Christiani 620 years ago, where he showed that asthma rates were greater in RTs compared with physical therapists. One hypothesis was put forward that maybe it was due to repetitive exposures to $\beta$ agonists.

* MacIntyre: I've been concerned about the caregiver issue for a while, not only with TOBI (tobramycin for inhalation), but amphotericin and cyclosporine, all of those agents. I'm not sure I want to be exposed, and pregnant women get particularly nervous about this. We use a BAN (breathactuated nebulizer) with a filter. The problem with the BAN is that, because it doesn't aerosolize during exhalation, you have the potential to give a whole lot more drug because you're not wasting it in the room. We try to get our pharmacy to cut the dose in half, and that freaks them out because they just dispense into the cup and have no idea how much of the cup actually goes into the patient. This notion of wasted drug is totally foreign to pharmacy, and it's been a struggle to try to adjust dosing for a BAN system.

Hess: Back to the topic at hand, NIV. With NIV, we can't use a BAN in line with the ventilator circuit. And to address what you just said as far as dosage, we do know that patients on inhaled aminoglycosides can develop renal toxicity with high doses.

† Fink: Great presentation. On secondhand exposure to antibiotics, I am probably as concerned about low-level deposition of the antibiotics on the sur- faces in the room (bed rails, sheets, table), which is actually having an effect in developing resistive organisms. I'm not sure if Cathy [O'Malley] will agree with me at all in her presentation, but it's very worrisome. I think that the bottom line is if you're spraying aerosols, you should probably filter them to protect the environment and the people. I think that for the HFNC, there's certainly variability between investigators. The key here is the combination, just like we learned with MDIs, the type of aerosol generator and the type of adapter and interface, and clearly, it's flow-related. So, Tim [Corcoran], your student's paper ${ }^{7}$ was really pivotal. It was done at $3 \mathrm{~L} / \mathrm{min}$, and it seems that the lower flow with high flow provides very effective aerosol delivery, and as flows go up, you have to compensate to get equivalent drug in. I'm wondering whether there's a role for nasal aerosol delivery with low-flow $\mathrm{O}_{2}$ delivery. Parion and UNC (University of North Carolina at Chapel Hill) did a study $^{8}$ reported at the ATS (American Thoracic Society) meeting in 2013 on low-flow nasal delivery of radiotagged hypertonic saline. They compared radio-tagged aerosol leaving a nasal cannula at $2 \mathrm{~L} / \mathrm{min}$, and lung deposition was close to $40 \%$ of the emitted dose, and the nasal deposition was very low. They looked at the LC Star and found very similar deposition at $40 \%$ of the dose emitted from the mouthpiece. So that's some evidence showing in vivo that these nasal aerosols get through the nose just fine.

Hill: I was going to ask you about HFNC and the one study ${ }^{9}$ you showed that actually looked at high flows, up to $60 \mathrm{~L} / \mathrm{min}$. I think that figure showed a pretty drastic reduction. But I think that was efficiency, wasn't it?

Hess: That was an absolute amount. So this is inspired albuterol dose in mg. The efficiency at best was $2.5 \%$.
Hill: There's got to be a rate or a unit there.

Hess: Good point. It's the duration of delivery for a unit dose ampule of albuterol (3 mL). They don't specify how much time it was that they collected drug. But for a 3-mL ampule, I'm thinking about 10 minutes.

Hill: What I'm supposed to take from this is at low flows, you get more drug than you get at high flows. Is that fair to say?

Hess: Correct. You actually bring up a very good point about rate of delivery. One might argue that over a 4-h continuous delivery, it might be as good or better than if you gave a single nebulizer treatment. Very good observation.

Hill: Thank you.

$\dagger$ Fink: It was intermittent doses, short.

Hess: Right, $10 \mathrm{~min}$ or something like that. If you're doing it continuously, you may still end up getting more drug delivered in a way that may be more desirable for the patient than to have a mask strapped to his or her face.

Berlinski: There was a pilot study in 2003 by Ari Soroksky, ${ }^{10}$ where he showed that NIV was better than sham in improving lung function in acute asthma.

Hess: I did not talk about that specific study, as I take that as more of a NIV study than an aerosol study.

Berlinski: Well, I know, but it explains Brandão's study, ${ }^{3}$ where you have the same deposition but better bronchodilation. Soroksky's study ${ }^{10}$ showed a 4-fold difference between NIV and sham in the percentage of subjects achieving the primary outcome.

Hess: And some of that might have been a mechanical bronchodilation effect. 
$\dagger$ Fink: To that point, Mike McPeck did a poster ${ }^{11}$ of a bench study looking at a comparison of jet and vibrating mesh nebulizers in NIV, and he looked at various levels of baseline and BPAP, reporting that deposition with the jet nebulizer varied with BPAP levels, whereas the mesh was pretty consistent. So it may be a function of the type of nebulizer against the pressure of NIV that makes an impact on the available dose.

* Neil R MacIntyre MD FAARC, Division of Pulmonary and Critical Care Medicine, Duke University, Durham, North Carolina, representing InspiRx.

$\dagger$ James B Fink PhD RRT FAARC, James B Fink LLC, San Mateo, California, and Division of Respiratory Therapy, Georgia State University, Atlanta, Georgia, representing Aerogen.

\section{REFERENCES}

1. Soma T, Hino M, Kida K, Kudoh S. A prospective and randomized study for improvement of acute asthma by non-invasive positive pressure ventilation (NPPV). Intern Med 2008;47(6):493-501.

2. Pollack CV Jr, Fleisch KB, Dowsey K. Treatment of acute bronchospasm with $\beta$-adrenergic agonist aerosols delivered by a nasal bilevel positive airway pressure circuit. Ann Emerg Med 1995;26(5):552-557.

3. Brandão DC, Lima VM, Filho VG, Silva TS, Campos TF, Dean E, de Andrade AD. Reversal of bronchial obstruction with bilevel positive airway pressure and nebulization in patients with acute asthma. J Asthma 2009; 46(4):356-361.

4. Iosson N. Images in clinical medicine. Nebulizer-associated anisocoria. N Engl J Med 2006;354(9):e8.

5. Schwartz AR, Kacmarek RM, Hess DR. Ambient contamination and caregiver protection during aerosol antibiotic administration (abstract). Respir Care 2002;47(9): 1037 (abstract).

6. Christiani DC, Kern DG. Asthma risk and occupation as a respiratory therapist. Am Rev Respir Dis 1993;148(3):671-674.
7. Bhashyam AR, Wolf MT, Marcinkowski AL, Saville A, Thomas K, Carcillo JA, Corcoran TE. Aerosol delivery through nasal cannulas: an in vitro study. J Aerosol Med Pulm Drug Deliv 2008;21(2): 181-188.

8. Rojas Balcazar JM, Donaldson SH, Navratil T, Bennett WD, Zeman K. Comparison of lung deposition of hypertonic saline using the Parion device and the Pari LC Star nebulizer in healthy, non-smoking adult volunteers. Poster Board B18. ATS 2013 International Congress, May 17-22, 2013, Philadelphia, Pennsylvania.

9. Perry SA, Kesser KC, Geller DE, Selhorst DM, Rendle JK, Hertzog JH. Influences of cannula size and flow rate on aerosol drug delivery through the Vapotherm humidified high-flow nasal cannula system. Pediatr Crit Care Med 2013;14(5):e250e256.

10. Soroksky A, Stav D, Shpirer I. A pilot prospective, randomized, placebo-controlled trial of bilevel positive airway pressure in acute asthmatic attack. Chest 2003;123(4): 1018-1025.

11. McPeck M. Enhanced aerosol drug delivery via vibrating mesh nebulizer during noninvasive ventilation. Respir Care 2012;57(10):1705. 